\title{
Metacognition and Body Image in Predicting Alexithymia in Substance Abusers
}

\author{
Samaneh Babaei ${ }^{1, *}$; Maryam Gharechahi ${ }^{2}$; Zohreh Hatami ${ }^{3}$; Shahryar Ranjbar Varandi ${ }^{4,5}$ \\ ${ }^{1}$ Deputy of Research and Technology, Zahedan University of Medical Sciences, Zahedan, IR Iran \\ ${ }_{2}^{2}$ Imam Khomeini Relief Foundation, Neyriz, IR Iran \\ ${ }^{3}$ Training and Education Organization of Daregaz, Daregaz, IR Iran \\ Training and Education Organization of Daregaz, Daregaz,
Training and Education Organization of Sari, Sari, IR Iran \\ ${ }^{5}$ Department of Clinical Psychology, Sari Branch, Islamic Azad University, Sari, IR Iran \\ *Corresponding author: Samaneh Babaei, Deputy of Research and Technology, Zahedan University of Medical Sciences, P. O. Box: 98197-13955, Zahedan, IR Iran. Tel/Fax: +98-5433522637, \\ E-mail:smnhbabaei3@gmail.com
}

Received: December 24, 2014; Revised: January 27, 2015; Accepted: February 26, 2015

\begin{abstract}
Background: Substance dependency is one of the biggest problems and worries of the world. It stunts the growth of society and causes various problems such as reduction in public health, increase in mortality, rise in social and domestic traumas, loss of educational and occupational opportunities, involvement with the judicial system, and development of the substance-abuse cycle.

Objectives: The aim of this study was to determine the role of metacognition and body image in predicting alexithymia in substance abusers.

Patients and Methods: The research sample included addicts (males and females aged 10 to 70 years) who referred to the addiction treatment and counseling centers of three Iranian cities of Zahedan, Sari, and Neyriz. Participants were selected by random sampling. The metacognitive strategy questionnaire (MCQ-30), physical self-description questionnaire (PSDQ), and Toronto alexithymia scale (TAS-20) were used for data collection. The hypotheses were tested using the Pearson's correlation method and regression analysis.

Results: According to the results of the current study, the highest correlation was between alexithymia and the cognitive awareness subscale $(r=0.305 ; P<0.01)$.There was no significant correlation between alexithymia and body image. Based on the multiple regression analysis, the three predictors explained $11 \%$ of the variance $\left(\mathrm{R}^{2}=0.11, \mathrm{~F}=3.981 ; \mathrm{P}<0.01\right)$. Cognitive awareness significantly predicted $9 \%$ of the variance $(\beta=0.305 ; \mathrm{P}<0.01)$, and the other subscales predicted about $2 \%$.

Conclusions: These findings demonstrated that metacognition had an important role in predicting alexithymia in the substance abusers, which underscores the necessity of precautionary measures.
\end{abstract}

Keywords: Cognition; Affective Symptoms; Body Image; Behavior, Addictive

\section{Background}

The use of natural and artificial substances has increased during the past few decades, which indicates the incidence of a new problem in physical and social health. The term "addicted individual" can be defined as one who has a very strong desire toward the use of addictive substances, regardless of their consequences (1). Substance abuse is a complicated issue with different dimensions. Therefore, any type of confrontation and intervention in this field needs to be conducted after extensive investigation.

In research on substance dependence, in addition to determining the different aspects of this problem, there are attempts to study and discover the variables that predict these disorders. Cash and Pruzinsky (2) and some other authors (3-5) have reported several risk factors related to substance abuse such as family conflict; educational problems; weakness in social relations; and psychologi- cal disorders, including depression, anxiety, and personality disorders. Furthermore, other significant factors are emotional problems, inability in the cognitive process of emotional information, and emotion-regulation problems (alexithymia) $(6,7)$. Alexithymia is a multifaceted construct consisting of difficulty in recognizing and describing emotions, difficulty in distinguishing between emotions and bodily tensions related to emotional excitement, and difficulty in expressing feelings for others. Individuals with this emotional problem are aware of their emotional experience but cannot distinguish the type of emotion. Although the prevalence rate of alexithymia in the general population is reported at about $10 \%$, there are higher levels of this emotional problem in disorders such as depression, anxiety, pain disorders, sexual disorders, educational problems, procrastination, substance abuse, and alcoholism (7-12). Consequently, the focus of the

Copyright (C) 2015, Zahedan University of Medical Sciences. This is an open-access article distributed under the terms of the Creative Commons Attribution-NonCommercial 4.0 International License (http://creativecommons.org/licenses/by-nc/4.0/) which permits copy and redistribute the material just in noncommercial usages, provided the original work is properly cited. 
current study was the role of alexithymia in substance abuse and its correlation with other variables linked to substance dependence disorder. One of the most important variables allied to substance abuse is metacognition beliefs, which include the beliefs that individuals harbor about their thoughts. Metacognition refers to the beliefs and attitudes of an individual about cognitive events like thoughts, emotions, memories, feelings, and other perceptual forces (13). According to the metacognition theory, substance abuse is an effective means of swiftly modifying cognitive events such as emotions, thoughts, and memories. According to Berthoz et al. (9), Swart et al. (14), and Bahramnejad et al. (1), the relationship between emotion and substance abuse may be mediated by metacognition. Along the same line, Saed et al. (13), in their research on substance addicts, found that metacognitive factors, thought suppression, and negative emotions were the predictors of substance dependence. Likewise, Hoffman and Spatariu (15), stated that in their study population, comprising individuals with severe emotional and cognitive deficits, there was an extreme tendency toward dangerous behaviors. According to two studies by Spada et al. $(16,17)$, emotion and cognition were the key factors in success and mental health and reducing psychological problems and risky behaviors like substance abuse. Bagby et al. (18) found that addicts with alexithymia showed less interest in self-seeking and analytical/cognitive activities. Taylor et al. (19) and Stanghellini and Ricca (20) also showed that deficit in cognitive processing and emotional order and the failure to differentiate internal feelings from physical emotions were reasons for the tendency toward substance abuse in individuals with emotional disorders. In addition to metacognition, body image is another psychological factor related to alexithymia (21). Body description and image encompass individuals' perceptions concerning their body and their attitudes toward thoughts, ideas, emotions, and behaviors (22). Body image influences the individual's mental/social quality of life, and many reactions of the individual depend on the imagination and the image that the individual has in his/her mind. Any negative attitude toward self-causes feelings of inadequacy and inability in various aspects of physical and mental health $(23,24)$. Researchers in one previous study (25) mentioned that body dissatisfaction can lead to a belief of imaginary defects in the body and that it finally renders the individual unable to cope with emotions and feelings and creates severe emotional problems. Cash and Pruzinsky (2) and Nye and Cash (6) believed that body dissatisfaction was a major concern inasmuch as it caused depression, obsession, and tendency to drug and suicide among their study populations. Petrides and Furnham (23) showed that deviated body image was able to influence psychological and physical health. Continuous dissatisfaction from body image is likely to lead to mental disorders such as anxiety, depression, mental distress, severe emotional problems, and tendency to drug abuse $(22,23,26,27)$. Research indicates that individuals who are competent regarding experience, recognition, and emotion are better equipped to adapt and show reasonable and logical reactions, while individuals with alexithymia tend to have difficulty in identifying and regulating their emotions. Additionally, alexithymia renders individuals prone to magnify their normal body emotions, misinterpret these emotions, and exhibit helplessness through physical complaints and high-risk behaviors, all of which are deemed risk factors for psychosomatic and mood disorders. In light of the above-mentioned findings, we sought to investigate the role of metacognition and body image with respect to alexithymia in individuals with substance abuse.

\section{Objectives}

The aim of this study was to determine the role of metacognition and body image in predicting alexithymia in substance abusers.

\section{Patients and Methods}

In this research, metacognition and body image were considered as the predictor variables and alexithymia as the criterion variable. The community of the study included all addicts referring to the addiction treatment and counseling centers of three Iranian cities of Zahedan, Sari, and Neyriz between 2013 and 2014. A sample of 175 subjects, comprised of 19 (10.7\%) females and 81 (87.6\%) males, were selected by random sampling. The instruments were the metacognitive strategy questionnaire (MCQ-30), Toronto alexithymia scale (TAS-20), and physical self-description questionnaire (PSDQ). The findings were analyzed using the Pearson correlation coefficient and multivariable regression models.

\subsection{Metacognitive Strategy Questionnaire (MCQ-} 30)

The MCQ-30, designed by Wells and Cartwright-Hatton (28), consists of 30 items to which each participant can respond with one of the four options of "disagree", "somewhat agree”, "agree”, and "completely agree”. Metacognition is made up of the following subscales:1) positive anxiety beliefs; 2) beliefs regarding uncontrollability and risk; 3) beliefs about cognitive qualifications; 4) negative anxiety beliefs; and 5) cognitive self-awareness. These subscales are of acceptable reliability and validity. Cronbach's alpha coefficient of this questionnaire is reported from 0.72 to 0.89 , and its test-retest reliability coefficient ranges from 0.76 to 0.80 with the correlation coefficient of the metacognitive questionnaire between 0.26 and 0.73 according to the anxiety scale of Spielberger et al. (29). Shirinzadeh Dastgiri et al. (30) measured Cronbach's alpha coefficient of this questionnaire for an Iranian sample at 0.91 for the total scale and at 0.71 to 0.87 for the subscales. Furthermore, after 4 weeks, its test-retest reliability coefficient was 0.73 for the total scale and 0.58 to 0.87 for the subscales. 
Babaei S et al.

\subsection{Toronto Alexithymia Scale (TAS-20)}

The TAS-20, first introduced by Bagby et al. (18), is a selfassessment questionnaire with 20 items to assess alexithymia. This questionnaire has three dimensions: 1 ) difficulty in the diagnosis and detection of emotions (7 items); 2) difficulty in expressing emotions (5 items); and 3) focusing on outside experiences ( 8 items). The questions are based on a 5-point Likert scale ranging from $1=$ completely agree to $5=$ completely disagree (31). Cronbach's coefficient for alexithymia in the Farsi version was 0.85 , and it stood at $0.82,0.75$, and 0.72 for the three subscales of difficulty in identifying emotions, difficulty in expressing feelings, and extrinsic thinking, respectively, all of which are good internal consistencies (31). Ghorbani et al.(32) calculated Cronbach's alpha coefficient for an Iranian sample population at 0.74 for difficulty in identifying emotions, at 0.61 for difficulty in expressing feelings, and at 0.50 for extrinsic thinking (32). Shahgholian et al. (33) measured the reliability of the total scale for an Iranian sample using split-half and test-retest at 0.74 and 0.72 , respectively, and the validity of the scale at 0.85 . The reliability of this questionnaire for the total scale was 0.79 .

\subsection{The Physical Self-Description Questionnaire (PSDQ)}

The PSDQ is a multidimensional, physical self-concept instrument designed to measure 11 scales, viz. strength, body fat, activity, endurance/fitness, sports competence, coordination, health, appearance, flexibility, physical self-concept, and global self-esteem. The revised form of this questionnaire includes 47 phrases and has good reliability and reproduction capacity. Body self-description includes 9 specific factors for body concept and self-esteem. Self-description includes 6 or 8 phrases and is presented such that the subject answers on a 6-point scale from right to wrong. Marsh (34) studied the validity and reliability of the PSDQ with two samples, including 315 and 395 high-school students, and observed that this test had the required validity for detecting self-concept factors and that its reliability was 0.80 by Cronbach's alpha.
Based on previous studies, Khanjani et al. (35), reported test-retest reliability of (PADQ) about 0.78 . This questionnaire was reexamined by Abdolmaleki et al. (36), who reported its reliability at 0.87 . The reliability range of the subscales varies from 0.50 to 0.80 .

\section{Results}

The mean and standard deviation of the variables are depicted in Table 1, and the coefficients of the variables are given in Table 2 . According to the results in Table 1, the mean of positive beliefs about worry and cognitive confidence (14.13) was higher than that of the other metacognition strategies.

The relationship between metacognitive beliefs, body image and alexithymia was investigated using the Pearson's correlation coefficient. According to Table 2, there was a significant correlation between most of the variables. As the correlation matrix shows, alexithymia was not correlated with body image, but there was a positive correlation between metacognitive beliefs and alexithymia. The highest correlation was between alexithymia and cognitive awareness $(\mathrm{r}=0.305 ; \mathrm{P}<0.01)$. Furthermore, there were no significant correlations between alexithymia and the subscale of risk uncontrollability. Multiple regression analysis was used to determine the effects of the common and specific variables (metacognitive strategies and body image) on predicting alexithymia.

According to Table 3, in the first stage, the factor of cognitive awareness was entered in the model, and it showed the most significant correlation. In the subsequent stages, positive beliefs about worry, need to control thoughts, and cognitive confidence were respectively entered in the model. The last factor added was body image. The best model was thus determined. Multiple regression analysis was used to test whether metacognition and body image significantly predicted the participants' alexithymia; it indicated the three predictors explained $11 \%$ of the variance $\left(\mathrm{R}^{2}=0.11, \mathrm{~F}=3.981 ; \mathrm{P}<0.01\right.$ ) (Tables 3 and 4$)$. The results also demonstrated that cognitive awareness significantly predicted $9 \%$ of the variance $(\beta=0.305 ; \mathrm{P}<0.01)$ and that the other subscales predicted about $2 \%$.

Table 1. Mean and Standard Deviation of the Study Measures ${ }^{\text {a }}$

\begin{tabular}{lc}
\hline Variables & Values \\
\hline Alexithymia & $59.18 \pm 14.50$ \\
\hline Body image & $18.16 \pm 38.24$ \\
\hline Metacognitive strategies & $67.81 \pm 17.49$ \\
\hline Positive beliefs about worry & $14.13 \pm 4.59$ \\
\hline Risk uncontrollability & $13.69 \pm 4.54$ \\
\hline Cognitive confidence & $14.13 \pm 4.64$ \\
\hline Need to control thoughts & $12.93 \pm 4.45$ \\
\hline Cognitive awareness & $12.94 \pm 4.26$ \\
\hline a Values are presented as mean \pm standard deviation. &
\end{tabular}


Babaei S et al.

\begin{tabular}{|c|c|c|c|c|c|c|c|c|}
\hline Variables & $\mathbf{1}$ & 2 & 3 & 4 & 5 & 6 & 7 & 8 \\
\hline Alexithymia & - & & & & & & & \\
\hline Body image & 0.068 & - & & & & & & \\
\hline Metacognitive strategies & $0.235^{\mathrm{b}}$ & $0.164^{c}$ & - & & & & & \\
\hline Positive beliefs about worry & $0.224^{b}$ & 0.092 & $0.778^{b}$ & - & & & & \\
\hline Risk uncontrollability & 0.053 & $0.268^{b}$ & $0.780^{b}$ & $0.468^{b}$ & - & & & \\
\hline Cognitive confidence & $0.135^{\mathrm{b}}$ & $0.222^{b}$ & $0.744^{b}$ & $0.505^{b}$ & $0.506^{b}$ & - & & \\
\hline Need to control thoughts & $0.208^{b}$ & 0.096 & $0.847^{b}$ & $0.531^{b}$ & $0.613^{b}$ & $0.531^{b}$ & - & \\
\hline Cognitive awareness & $0.305^{b}$ & -0.053 & $0.739^{b}$ & $0.512^{b}$ & $0.438^{b}$ & $0.328^{b}$ & $628^{b}$ & - \\
\hline
\end{tabular}

$\mathrm{a} n=175$.
$\mathrm{b}=0.01$

c $\mathrm{P}<0.05$.

Table 3. The Results of Multiple Regression for the Prediction of Alexithymia According to Metacognitive Beliefs and the Body Image Subscales

\begin{tabular}{|c|c|c|c|c|c|c|c|}
\hline Variables & $\beta$ & $\mathbf{t}$ & $\mathbf{P}$ & $\mathbf{F}$ & $\mathrm{R}$ & $\mathbf{R}^{2}$ & $\begin{array}{c}\text { Adjusted } \\
\mathbf{R}^{\mathbf{2}}\end{array}$ \\
\hline \multicolumn{8}{|l|}{ Model 1} \\
\hline Cognitive awareness & 0.305 & 4.202 & 0.000 & 17.653 & 0.305 & 0.093 & 0.088 \\
\hline \multicolumn{8}{|l|}{ Model 2} \\
\hline Cognitive awareness & 0.258 & 3.053 & 0.003 & 9.409 & 0.315 & 0.099 & 0.089 \\
\hline Positive beliefs about worry & 0.091 & 1.072 & 0.285 & & & & \\
\hline \multicolumn{8}{|l|}{ Model 3} \\
\hline Cognitive awareness & 0260 & 2.686 & 0.008 & 6.236 & 0.315 & 0.099 & 0.083 \\
\hline Positive beliefs about worry & 0.092 & 1.026 & 0.306 & & & & \\
\hline Need to control thoughts & -0.004 & -0.041 & 0.967 & & & & \\
\hline \multicolumn{8}{|l|}{ Model 4} \\
\hline Cognitive awareness & 0261 & 2.672 & 0.008 & 4.651 & 0.315 & 0.099 & 0.078 \\
\hline Positive beliefs about worry & 0.090 & 0.947 & 0.345 & & & & \\
\hline Need to control thoughts & -0.007 & -0.065 & 0.948 & & & & \\
\hline Cognitive confidence & 0.007 & 0.073 & 0.942 & & & & \\
\hline \multicolumn{8}{|l|}{ Model 5} \\
\hline Cognitive awareness & 0.276 & 2.791 & 0.006 & 3.981 & 0.326 & 0.106 & 0.080 \\
\hline Positive beliefs about worry & 0.087 & 0.916 & 0.361 & & & & \\
\hline Need to control thoughts & -0.002 & -0.021 & 0.983 & & & & \\
\hline Cognitive confidence & -0.022 & -0.231 & 0.812 & & & & \\
\hline Body image & 0.080 & 1.054 & 0.293 & & & & \\
\hline
\end{tabular}

Table 4. Summary of the Regression Model Between the Dependent Variable (Alexithymia) and the Independent Variables (Metacognitive Beliefs and Body Image)

\begin{tabular}{lccccc}
\hline Changing Source & $\mathbf{F}$ & P-Value & $\mathbf{R}$ & $\mathbf{R}^{2}$ & Adjusted R $^{2}$ \\
\hline Regression remaining & 3.981 & $<0.01$ & 0.326 & 0.106 & 0.080 \\
\hline
\end{tabular}

\section{Discussion}

In the present study, the findings arising from the relationship between metacognition and alexithymia in the substance abusers were concordant with the studies of Cash and Pruzinsky (2), Bagby et al. (18), Luminet 
Babaei S et al.

et al. (3), Lane et al. (4), Nye and Cash (6), and Dubey et al. (7), showing that impaired metacognitive beliefs in their study populations prompted non-beneficial coping strategies, leading to cognitive interactions and ineffective emotional and behavioral reactions forming the basis and context for addiction. Also, Abbasi et al. (37), Swart et al.(14), Saed et al.(13), Besharat (31), Hoffman and Spatariu (15), and Bagby et al. (18) reported that substance abuse was an effectual means of swiftly modifying cognitive events such as feeling, expression, and regulation of emotion in alexithymia. Furthermore, Hoffman and Spatariu (15) identified emotion and cognition as key factors in the success of mental health and reducing risk behaviors such as substance abuse and psychological problems.

Our multiple regression analysis results showed that out of all the metacognitive beliefs, cognitive awareness was the best predictor for alexithymia and also for the tendency toward addiction. It can, thus, be argued that metacognitive beliefs and especially the metacognitive beliefs concerning cognitive awareness can cause a tendency toward using drugs by affecting the individual's emotion controlling power and decision-making and causing them to use non-adaptive coping strategies.

One probable reason for the emotional problems of the addicts in the current study is body image insofar as individuals' perception of their body size and fitness is associated with their thinking and feeling about other people's views of their body $(38,39)$. In contrast to the studies by De Berardis et al. (40), Mohamadi and Sajadinejad (41), and Spangler and Stice (42), there was no relationship between alexithymia and body image in our sample. It is important to note that in contrast to our study, most of the previously conducted investigations such as those by Adami et al. (43), Assar et al. (39), Noli et al. (44), Abdolmaleki et al. (36), Moss and Harris (45), von Soest et al. (27), Phillips (46), Frederick et al. (47), and Zojaji et al. (48) took into account body image perception (body size) and psychological problems such as obesity, anxiety, and depression. In addition, most previous studies considered psychosomatic and mood disorders as the most important risk factors for alexithymia (27, 36, 39, 43-48). We sought to determine the role of metacognition and body image in predicting alexithymia in substance abusers; however, further research is required to shed sufficient light on this issue.

Given the concerns regarding the harmful effects of substance abuse and addiction and the old adage "Prevention is the best treatment", it is vitally important that the causes of tendency toward addiction be identified so that more effective preventive strategies can be devised to assist health care practitioners in the field of primary prevention.

\section{Acknowledgements}

All the authors of this paper thank the welfare department and addiction treatment centers of Sari, Mazandaran province, and Neyriz, Fars province. Many thanks are also due to the addiction treatment centers of Baharan hospital, Zahedan, Sistan and Baluchestan Province.

\section{Authors' Contributions}

Samaneh Babaei conceived, designed, and performed the experiments and analyzed the data. Maryam Gharechahi designed the experiments and gathered the data. Shahryar Ranjbar Varandi, Zohreh Hatami, and Maryam Gharechahi gathered the data.

\section{References}

1. Bahramnejad A, Rabani-Bavojdan M, Rabani-Bavojdan M. The relationship of metacognitive beliefs and tendency to addiction in sistan and baluchistan university, zahedan, iran. Addict Health. 2012;4(1-2):65-72.

2. Cash TF, Pruzinsky T. Body images: Development, deviance, and change.New York: Guilford Press; 1990. p. 361.

3. Luminet O, Bagby RM, Wagner H, Taylor GJ, Parker JD. Relation between alexithymia and the five-factor model of personality: a facet-level analysis. J Pers Assess. 1999;73(3):345-58.

4. Lane RD, Ahern GL, Schwartz GE, Kaszniak AW. Is alexithymia the emotional equivalent of blindsight? Biol Psychiatry. 1997;42(9):834-44.

5. Sadock BJ, Sadock VA. Kaplan and Sadock's synopsis of psychiatry: Behavioral sciences/clinical psychiatry. 10 ed. Lippincott Williams \& Wilkins; 2011.

6. Nye S, Cash TF. Outcomes of manualized cognitive-behavioral body image therapy with eating disordered women treated in a private clinical practice. Eat Disord. 2006;14(1):31-40.

7. Dubey A, Pandey R, Mishra K. Role of emotion regulation difficulties and positive/negative affectivity in explaining alexithymia-health relationship: an overview. Indian J of Social Sci Res. 2010;7(1):20-31.

8. Berthoz S, Consoli S, Perez-Diaz F, Jouvent R. Alexithymia and anxiety: compounded relationships? A psychometric study. Eur Psychiatry. 1999;14(7):372-8.

9. Berthoz S, Lalanne C, Crane L, Hill EL. Investigating emotional impairments in adults with autism spectrum disorders and the broader autism phenotype. Psychiatry Res. 2013;208(3):257-64.

10. Hintikka J, Honkalampi K, Lehtonen J, Viinamaki H. Are alexithymia and depression distinct or overlapping constructs?: a study in a general population. Compr Psychiatry. 2001;42(3):234-9.

11. Thorberg FA, Young RM, Sullivan KA, Lyvers M. Alexithymia and alcohol use disorders: a critical review. Addict Behav. 2009;34(3):237-45.

12. Honkalampi K, Koivumaa-Honkanen H, Lehto SM, Hintikka J, Haatainen K, Rissanen T, et al. Is alexithymia a risk factor for major depression, personality disorder, or alcohol use disorders? A prospective population-based study. J Psychosom Res. 2010;68(3):269-73.

13. Saed O, Purehsan S, Aslani J, Zargar M. The Role of Thought Suppression, Meta-Cognitive Factors and Negative Emotions in Prediction of Substance Dependency Disorder. Res On Addiction. 2011;5(18):69-84.

14. Swart M, Kortekaas R, Aleman A. Dealing with feelings: characterization of trait alexithymia on emotion regulation strategies and cognitive-emotional processing. PLoS One. 2009;4(6):e5751.

15. Hoffman B, Spatariu A. The influence of self-efficacy and metacognitive prompting on math problem-solving efficiency. Contemporary Educational Psychology. 2008;33(4):875-93.

16. Spada MM, Caselli G, Wells A. Metacognitions as a predictor of drinking status and level of alcohol use following CBT in problem drinkers: a prospective study. Behav Res Ther. 2009;47(10):882-6.

17. Spada MM, Hiou K, Nikcevic AV. Metacognitions, Emotions, and Procrastination. Journal of Cognitive Psychotherapy. 2006;20(3):319-26.

18. Bagby RM, Parker JD, Taylor GJ. The twenty-item Toronto Alexithymia Scale--I. Item selection and cross-validation of the factor 
structure. J Psychosom Res. 1994;38(1):23-32.

19. Taylor GJ, Bagby RM, Parker JD. Disorders of affect regulation: Alexithymia in medical and psychiatric illness. Cambridge: Cambridge University Press; 1999.

20. Stanghellini G, Ricca V. Alexithymia and schizophrenias. Psychopathology. 1995;28(5):263-72.

21. Borzekowski DL, Bayer AM. Body image and media use among adolescents. Adolesc Med Clin. 2005;16(2):289-313.

22. Cash TF, Theriault J, Annis NM. Body Image in an Interpersonal Context: Adult Attachment, Fear of Intimacy and Social Anxiety. Journal of Social and Clinical Psychology. 2004;23(1):89-103.

23. Petrides KV, Furnham A. Trait emotional intelligence: psychometric investigation with reference to established trait taxonomies. European Journal of Personality. 2001;15(6):425-48.

24. Richardson LP, Garrison MM, Drangsholt M, Mancl L, LeResche L. Associations between depressive symptoms and obesity during puberty. Gen Hosp Psychiatry. 2006;28(4):313-20.

25. Moniaux N, Chakraborty S, Yalniz M, Gonzalez J, Shostrom VK, Standop J, et al. Early diagnosis of pancreatic cancer: neutrophil gelatinase-associated lipocalin as a marker of pancreatic intraepithelial neoplasia. Br J Cancer. 2008;98(9):1540-7.

26. Izgic F, Akyuz G, Dogan O, Kugu N. Social phobia among university students and its relation to self-esteem and body image. Can JPsychiatry. 2004;49(9):630-4.

27. von Soest T, Kvalem IL, Roald HE, Skolleborg KC. The effects of cosmetic surgery on body image, self-esteem, and psychological problems. J Plast Reconstr Aesthet Surg. 2009;62(10):1238-44.

28. Wells A, Cartwright-Hatton S. A short form of the metacognitions questionnaire: properties of the MCQ-30. Behav Res Ther. 2004;42(4):385-96.

29. Spielberger C, Gorsuch RL, Lushene RE. Manual for the State/Trait Anxiety Inventory (version espanola, TEA, 1982). Palo Alto, CA: Consulting Psychologists Press; 1970.

30. Shirinzadeh Dastgiri S, Goudarzi MA, Rahimi C. Study Of Factor Structure, Validity And Reliability Of Metacognition Questionnaire-30. J Psychol. 2009;12(1(48)):445-61.

31. Besharat MA. Reliability and factorial validity of a Farsi version of the 20-item Toronto Alexithymia Scale with a sample of Iranian students. Psychol Rep. 2007;101(1):209-20.

32. Ghorbani N, Bing M, Watson PJ, Davison H, Mack D. Self-reported emotional intelligence: Construct similarity and functional dissimilarity of higher-order processing in Iran and the United States. International Journal of Psychology. 2002;37(5):297-308.

33. Shahgholian M, Moradi A, kafee S. The relionship alexithymia with expersive emotion styles. General health Iran Psychiatr Clin. 2007;19(3):238-48.
34. Marsh HW. Physical Self Description Questionnaire: stability and discriminant validity. Res Q Exerc Sport. 1996;67(3):249-64.

35. Khanjani Z, Babapour J, Saba G. Investigating Mental Status and Body Image in Cosmetic Surgery Applicants in Comparison with Non-applicants. The journal of Shahid-Beheshti University of Medical Sciences. 2012;20(2):237-48.

36. Abdolmaleki Z, Sedghpour SB, Bahram A, Abdolmaleki F. Validity and Reliability of The Physical Self-Description Questionnaire Among Adolescent Girls. J Applied Psychol. 2011;4(16):42-55.

37. Abbasi M, Bagyan MJ, Dehghan H. Cognitive failure and alexithymia and predicting high-risk behaviors of students with learning disabilities. Int J High Risk Behav Addict. 2014;3(2):e16948.

38. Baldaro B, Rossi N, Caterina R, Codispoti M, Balsamo A, Trombini $\mathrm{G}$. Deficit in the discrimination of nonverbal emotions in children with obesity and their mothers. Int J Obes Relat Metab Disord. 2003;27(2):191-5.

39. Assar KH, Roshan R, Khalaj A, Mohammadi J. A Study On The Alexithymia And Body Image In The Obese, Over-Weight And Normal Waight Subjects. J OF APPLIED PSYCHOLOGY . 2011;4(16):42-55.

40. De Berardis D, Carano A, Gambi F, Campanella D, Giannetti P, Ceci A, et al. Alexithymia and its relationships with body checking and body image in a non-clinical female sample. Eat Behav. 2007;8(3):296-304.

41. Mohamadi N, Sajadinejad M. Relationship between worry about body image, negative evaluation fear, self-esteem and social phobia. Journal of Psychology (Tabriz University). 2007;5(2):55-7.

42. Spangler DL, Stice E. Validation of the beliefs about appearance scale. Cognitive Therapy and Research. 2001;25(6):813-27.

43. Adami GF, Campostano A, Ravera G, Leggieri M, Scopinaro N Alexithymia and body weight in obese patients. Behav Med. 2001;27(3):121-6.

44. Noli G, Cornicelli M, Marinari GM, Carlini F, Scopinaro N, Adami GF. Alexithymia and eating behaviour in severely obese patients. JHum Nutr Diet. 2010;23(6):616-9.

45. Moss TP, Harris DL. Psychological change after aesthetic plastic surgery: a prospective controlled outcome study. Psychol Health Med. 2009;14(5):567-72.

46. Phillips KA. Body dysmorphic disorder: the distress of imagined ugliness. Am J Psychiatry. 1991;148(9):1138-49.

47. Frederick DA, Lever J, Peplau LA. Interest in cosmetic surgery and body image: views of men and women across the lifespan. Plast Reconstr Surg. 2007;120(5):1407-15.

48. Zojaji R, Javanbakht M, Ghanadan A, Hosien H, Sadeghi H. High prevalence of personality abnormalities in patients seeking rhinoplasty. Otolaryngol Head Neck Surg. 2007;137(1):83-7. 